\title{
Application of Coal Rock Analysis in Coking Productions
}

\author{
Wu Xianxi, Chen Guoqing, Liu Binbin, Wu Son** \\ College of Chemistry and Chemical Engineering, Guizhou University, Guiyang, China \\ Email address: \\ wuxx2012@sina.com (Wu Xianxi), 2670815803@qq.com (Wu Xianxi), lbbemail@163.com (Liu Bin Bin), 2670815803@qq.com (Wu Son) \\ ${ }^{*}$ Corresponding author
}

\section{To cite this article:}

Wu Xianxi, Chen Guoqing, Liu Binbin, Wu Son. Application of Coal Rock Analysis in Coking Productions. American Journal of Applied Chemistry. Vol. 8, No. 1, 2020, pp. 1-5. doi: 10.11648/j.ajac.20200801.11

Received: January 4, 2020; Accepted: February 4, 2020; Published: February 18, 2020

\begin{abstract}
In the coking industry, the variety and quality of single coal is the basis for influencing the quality of coal blending and ultimately the quality of coke products. Nowadays, some coking plants generally use industrial analysis methods to determine the quality of coal varieties and coal blending. However, using industrial analysis method alone cannot ensure that the variety quality identification of single coal and mixed coal is correct and reliable, therefore, there is no guarantee of coking coal blending and the final coking quality. Identifying coal by means of coal-rock analysis and distinguishing mixed coal can make up for the deficiency of industrial analysis in testing coal quality and types of coal. At the same time, according to the reflectivity of the vitrinite of coal can be additive, using synthetic coal reflectance distribution map to guide coal coking, can predict, improve and raise the quality of coke products. In this paper, some examples are given to identify coal type and distinguish mixed coal by reflectivity of coal vitrinite combined with industrial analysis method. At the same time, the method and example of applying synthetic coal reflectivity distribution map to guide coking coal to improve coke quality are also given. Finally noted, when using coal-rock method to guide coking and predict coke quality, it must be tested no arbitrary application.
\end{abstract}

Keywords: Analysis of Coal Rock, Vitrinite Reflectance, Reflectance Distribution Map, Single Coal, Mixed Coal, Coal Blending; Coking

\section{Introduction}

Because of the different coal sources, different resource conditions and different quality control methods of coal sources, the quality of single coal entering coking plant fluctuates greatly, and there are mixed coal phenomena in different degrees. In addition, in order to pursue high profits, some coal washing plants deliberately mix some inferior coal into high quality coal, resulting in the fluctuation of the quality of a single kind of coal. If the washing quality of coking coal is poor and there is mixed coal phenomenon, it will directly affect the quality of coke produced [1,2]. This paper introduces the application of coal and rock theory in coking plants in a certain area. The maximum reflectivity of vitrinite group of coal is used to detect and control the quality of coking coal to prevent the phenomenon of coal mixing. At the same time, the reflectivity distribution map is used to guide the coking production of coal blending, so that the coke quality can be improved $[3,4]$.

\section{Application of Coal Petrology in Coal Quality and Coking Coal Blending Analysis}

\subsection{Coal Rock and Coal Petrology}

Coal is a solid fuel, a flammable organic sedimentary rock. The study of coal rock is to treat coal as a kind of organic rock which is composed of various components and structures with different properties and is complex and changeable in nature.

Coal petrology is a subject that studies the change of coal properties and its application, it regards coal as a kind of organic rock with complex and changeable properties, which is composed of many kinds of organic rocks with different components and structures. In coking industry, coal petrology is mainly used to evaluate coal quality, identify mixed coal, guide coking and blending, and predict coke quality $[5,6]$. 


\subsection{Coal Rock Macerals}

Coal can form different appearance and properties in peat due to the different conditions of biochemical action in peat stage. The lithofacies components that can be observed under a microscope are called microcomponents. According to the origin and properties of the original material, the organic macerals can be divided into vitrinite group, filamentous group and shell group [6-9]:

1. Vitrinite group: A component formed by gelation of plant residues. Wood fiber tissue of plant residues in an environment of a more water and less oxygen and anaerobic bacteria, vitrinite component formed by the gelation of water absorption expansion and biochemistry. It is the most important maceral in coal. The vitrinite content of most coalfields in China is about $60 \% \sim 80 \%$. Vitrinite is the most important melting component in coal, and its adhesion varies with the change of metamorphism, and its metamorphism can be accurately measured by reflectivity. The reflectivity of vitrinite of coking coal is about $0.65 \sim 2.00$.

2. Filamentous group. It is obtained by silk carbonation of lignin, cellulose and other components of plants. It is also a common maceral in coal, but its content is less than vitrinite. filamentous formation of most coalfields in China the amount is about $10 \%$ to $20 \%$, filamentous group (including silk charcoal, opaque matrix) no stickiness. The filamentous group is a completely inert component in the coking process, the structure was almost unchanged and transferred into the coke pore wall.
3. Shell group: The cuticle, resin, or spore in the remains of a plant and so on, most of them are stored in coal on their original state. The remains of the plants observed under the microscope that maintain their own shape and structure are called shell groups.

\subsection{Evaluation of Coal Quality}

The combination of common industrial analysis methods with analysis of coal petrology can evaluate coal quality comprehensively and accurately $[10,11]$. Coal metamorphism and coal rock composition are the main factors affecting coal quality. The metamorphic course of the same coal seam there is generally no difference in degree, but the coal quality in different parts of the same layer of coal may be different, this is generally due to its different composition of coal-rock. Different coal seams in the same coalfield will cause coal quality due to the different coal-rock composition differences [12].

In addition, the coal quality of coal is different because of the different content of some micro-component in coal-rock composition. It is difficult to make an accurate assessment of all kinds of coal quality without coal petrology identification.

According to their own research results, some research institutions and some scholars find that there is a general corresponding relationship between the average maximum reflectivity of vitrinite and all kinds of coal in the current coal classification. The maximum reflectance distribution of vitrinite with different metamorphic degree of bituminous coal is proposed. The representative 2 division schemes are presented in Table 1 [13].

Table 1. The maximum reflectance distribution of vitrinite with different.

\begin{tabular}{llllll}
\hline metamorphic degree of bituminous coal\% & & & & \\
\hline \multirow{2}{*}{ Division scheme } & \multicolumn{6}{l}{$\mathbf{R}_{\text {max }}^{\mathbf{0}}$} & & & & \\
\cline { 2 - 6 } & Gas Coal & fat coal (1/3) & Coke coals & Thin coal & Lean coal \\
\hline scheme 1 & $0.6-0.885$ & $0.9-1.2$ & $1.23-1.42$ & $1.59-1.71$ & - \\
scheme 2 & $1.8-2.35$ & $0.61-0.84$ & $0.84-1.13$ & $1.13-1.6$ & $1.6-1.8$ \\
& $1.9-2.5$ & $0.65-0.9$ & $0.9-1.2$ & $1.2-1.7$ & $1.7-1.9$ \\
\hline
\end{tabular}

From Table 1, it can be seen that the average reflectivity and the distribution range of reflectivity of fat coal and $1 / 3$ coke coal basically coincide with each other. It is impossible to distinguish between fat coal and 1 / 3 coke coal by means of reflectivity average and reflectivity distribution map. At this time, we must use the $\mathrm{G}, \mathrm{Y}$ value of coal as the auxiliary decision index.

\subsection{Identification of Mixed Coal}

The so-called mixed coal is a single kind of washed coal mixed with different metamorphism coal. The way of mixing can be coal with similar metamorphism or coal with different metamorphism. At present, most coking plants use coal blending for coking. It is best to use a single kind of coal in coking coal blending, and it is required that there is no great fluctuation in each batch of coal at the same coal point, otherwise it will affect the quality of the blending coal, and then affect the coke quality.
Coal samples are often encountered in coking production not as a single coal, but as a mixture of coal. This may be caused by many factors, such as mining, washing, transportation, sales and so on, driven by technical conditions and economic interests. No matter what the reason, the mixed coal is disadvantageous to the coking production. Therefore, in order to normally use coal blending technology and stabilize coke quality, coking plant need to identify mixed coal. At present, the identification of mixed coal in the world is mainly based on the vitrinite reflection rate histogram of coal [14]. The vitrinite reflectivity histogram can directly reflect the mixing of coal with different metamorphism.

The vitrinite reflectivity histogram of a single coal is a single peak, and the distribution is narrow, the standard deviation is small, and the standard deviation $\mathrm{S} \leq 0.1$. Compared with single coal, the vitrinite reflectivity histogram of mixed coal has the following characteristics [15].

1. The vitrinite reflectivity histogram of mixed coal composed 
of more than two kinds of coal with obvious difference in metamorphism is obviously bimodal or multipeak.

2. A mixed coal composed of more than two kinds of coal with similar metamorphism but obviously different composition of coal and rock, and the properties of the two kinds of coal are generally obviously different. Usually, the vitrinite reflectivity histogram of the mixed coal is a single peak, and the standard deviation of the single peak measurement value is large.

3. The reflectivity histograms of coal vitrinite or the composition of coal and rock components in different batches of the same coal supply unit have significantly changed, This will directly reflect its role in coal blending. This situation should also be regarded as a mixed coal.

\section{Experiment}

\subsection{Experimental Methods and Equipment}

Sampling and sample preparation by GB/T16773-2008 «preparation method of coal-rock analytical samples».

According to GB/T 6948-2008 «coal measuring method of vitrinite reflectance microscope». Determination random reflectance of vitrinite of coking coal, Rran, by using the German Zeiss research-grade digital coal-rock analysis system MY600.

Finally, the vitrinite reflectivity histogram of various coal samples is drawn.

\subsection{Determination of Coal Quality}

(1) Test analysis

The vitrinite reflectance of coal increases with the increasing degree of coalification high, therefore, vitrinite reflectivity distribution map is the only method to identify the mixed coal. The vitrinite reflectance and industrial analysis of experimental coal were compared.

Table 2 shows the industrial analysis of coal sample quality forecast and the results of vitrinite reflectance measurement according to Table 1.

Table 2. Industrial analysis of coal quality prediction and comparison of vitrinite reflectance.

\begin{tabular}{llllllll}
\hline Number coal sample & $\mathbf{A}_{\mathbf{a d}} / \mathbf{\%}$ & $\mathbf{V}_{\mathbf{a d}} / \mathbf{\%}$ & $\mathbf{S}_{\text {tad }} / \mathbf{\%}$ & $\mathbf{y} / \mathbf{m m}$ & $\mathbf{G}$ & $\mathbf{R}_{\mathbf{m a x}}$ \\
\hline 1 & gas coal & 9.46 & 39.10 & 0.81 & 19.9 & 86.2 & 0.918 \\
2 & fat coal & 9.47 & 29.67 & 0.38 & 25.4 & 87.8 & 1.009 \\
3 & coking coal & 9.77 & 20.49 & 0.51 & 16.5 & 84.2 & 1.112 \\
4 & coking coal & 10.36 & 21.54 & 0.94 & 16.17 & 72.23 & 1.422 \\
5 & anthracite & 9.84 & 7.52 & 0.86 & & Singlefatcoal & Complexcoalblending \\
\hline
\end{tabular}

As can be seen from Table 1, most of the results of coal quality prediction and industrial analysis are consistent, but vitrinite reflectance detection most of the coal is mixed coal. Let's take a look at the test results for each sample.

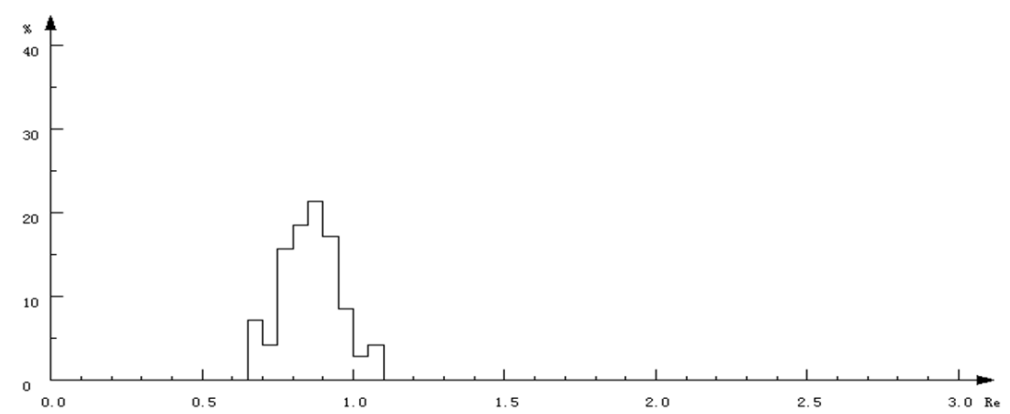

Figure 1. Industrial analysis is gas coal. Coal rock analysis is reflectivity histogram of fat coal (sample No. 1 in Table 2).

Figure 1 shows the industrial analysis identified as gas coal (sample No. 1 of Table $2, \mathrm{vad} / \%=39.10, \mathrm{~g}=86$ ). The reflectance histogram re of coal-rock analysis is $0.65-1.1$, according to table 1 , the scheme of 1 and 2 should be fat coal

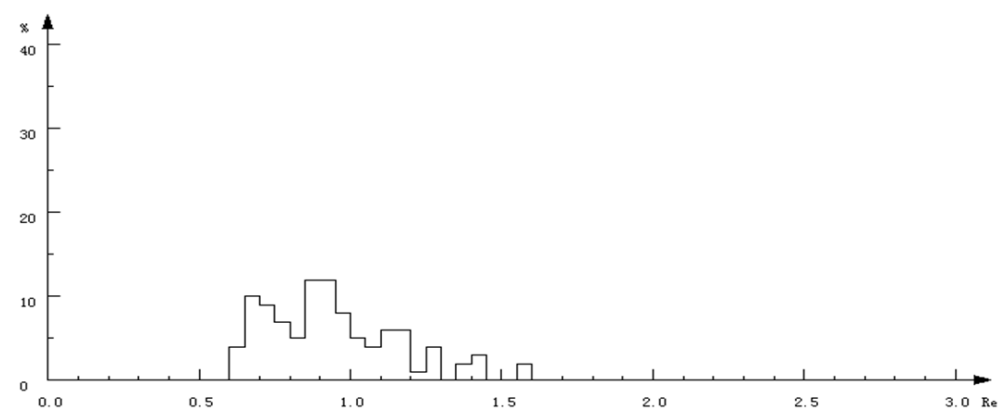

Figure 2. Industrial analysis as fat coal (sample 2 in Table 2), the reflectivity histogram of coal rock analysis as mixed coal. with a single layer of coal. The same comparison shows is identified as fat coal by industrial analysis (sample 2 of Table 2 ), but the reflectivity histogram of coal-rock analysis is obviously multi-peak. 


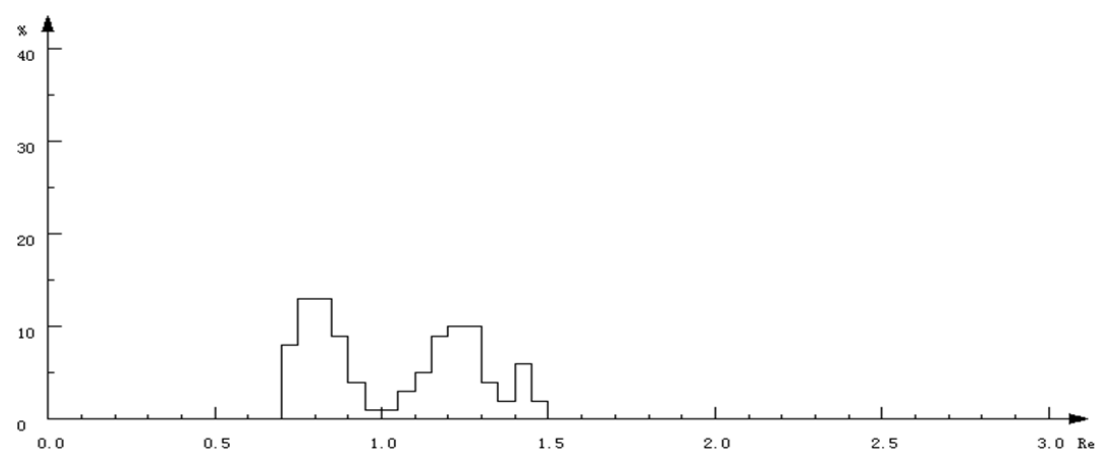

Figure 3. Industrial analysis as coke coal (sample 3 in Table 2), the reflectivity histogram of coal rock analysis as fat coal.

It's histograms of severely complex coal mixtures of gas coal, fat coal, coke coal, lean coal. Figure 3 shows that industry analysis identified as coke coal (sample 3 in Table 2), but the reflectivity histogram of coal and rock analysis is fat coal and coke coal simple mixed coal histogram, fat coal and

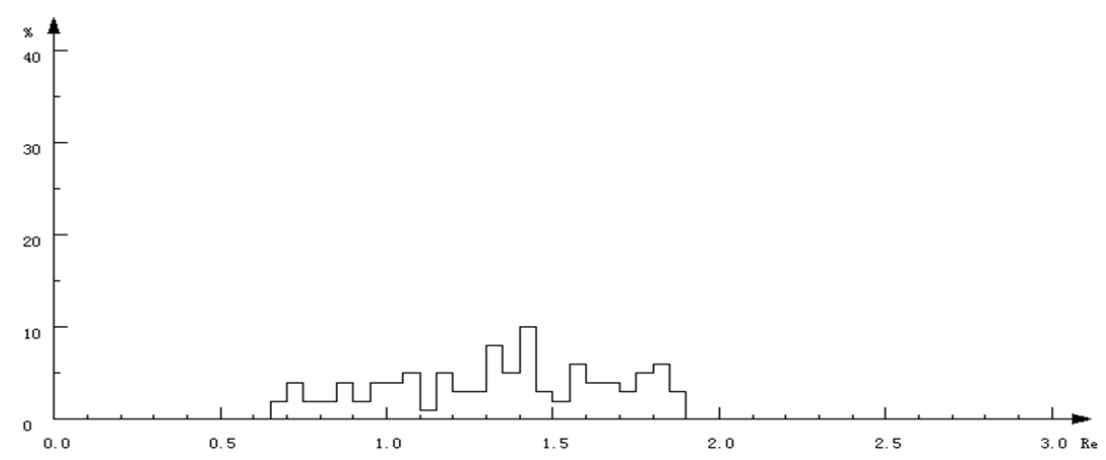

Figure 4. Industrial analysis as fat coal (sample 4 in Table 2), the reflectivity histogram of coal-rock analysis as mixed coal.

\subsection{Directing Coking with Coal Reflectance Distribution Map}

At present, most of the better coal blending methods in various countries have been applied to coal-rock coal blending principle.

In the current shortage of coal resources, mixed coal serve as a single coking coal is very common. However, the mixed coal is different from the single coal, and can not play the role of a single coal of the corresponding grade in coking production [16]. Therefore, in the formulation of coal blending programmes, it is necessary to make a reasonable coal blending scheme with full reference to the actual proportion of each coal species in the reflectivity distribution map. This goal is realized by combining the reflectivity distribution map of a single kind of coal into the reflectivity distribution map of mixed coal. It is on the basis that the reflectivity of the vitrinite is additive

Practice of coal distribution maps. A map of the distribution of certain types of coal on a composite coal multiply the ordinate value by the ratio of the single coal to the combined coal to obtain a new ordinate value. sum the new ordinate values for all single coals to obtain the superposition ordinate values. Draw the distribution map according to the superimposed longitudinal coordinate value [17].

The distribution of reflection rate of mixed coal must be coke coal all account for a considerable proportion. Figure 4 is the industrial analysis as coke coal (Table 2 sample 4), but coal rock analysis as complex mixed coal with coke coal as the main coal blending in coking coal balanced, that is, the deviation degree between vitrinite reflectivity value and its average value should be reasonable. This can ensure the good continuity of the plastic state of the blending coal during the coking process. The reflectivity distribution map of vitrinite composition of each single coal in coal blending scheme can be obtained by weighted average. As far as possible to blend coal vitrinite maximum reflectivity of the curve distribution uniform, no large notch, curve successive.

Finally, the coal blending ratio is determined according to the proportion of individual coal in the synthetic diagram. Figure 5 is an ideal matching coal reflectance curve for reference [4].

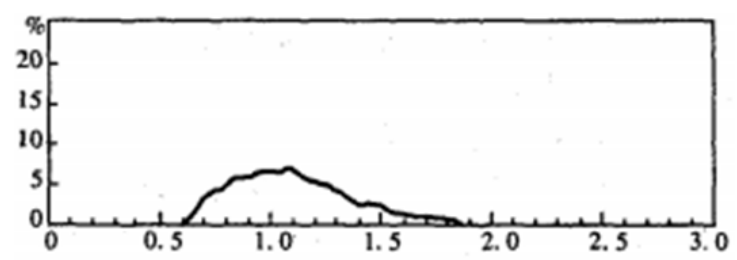

Figure 5. Ideal curve of blending coal reflectance.

\subsection{Coal Blending Coking Experiment}

Coal blending scheme 1: Coke (1) 32\%; Coke (2) $8 \%$; Fat coal $41 \%$; Gas coal $12 \%$; Anthracite $7 \%$.

The reflectivity distribution map of the coal blending made of the five kinds of coal mentioned above is shown in figure 6 . 


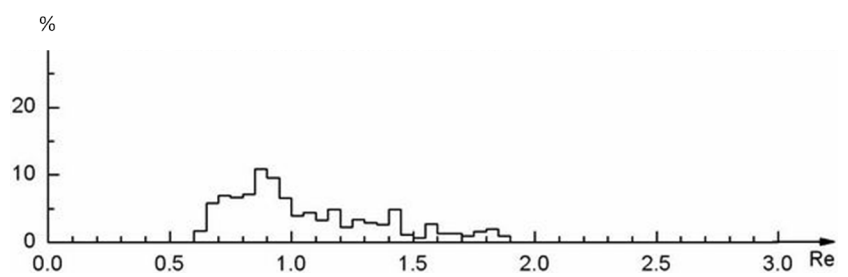

Figure 6. A histogram of vitrinite reflectance of coal blending scheme 1.

As you can see from figure 6, comparison with ideal reflectivity curve of coal blending, the coking coal content in blending coal is low and fat coal content high. The proportion of coke fat should be adjusted properly to ensure the quality of coal blending.

After adjust the ratio the formulation of coal blending programme 2 .

Coal blending scheme 2: Coke (1) 35\%; Coke (2) $9 \%$; Fat coal 35\%; Gas coal 13\%; Anthracite $8 \%$.

The reflectivity distribution map of the coal blending made of the programme 2 of coal mentioned above is shown in figure 7 .

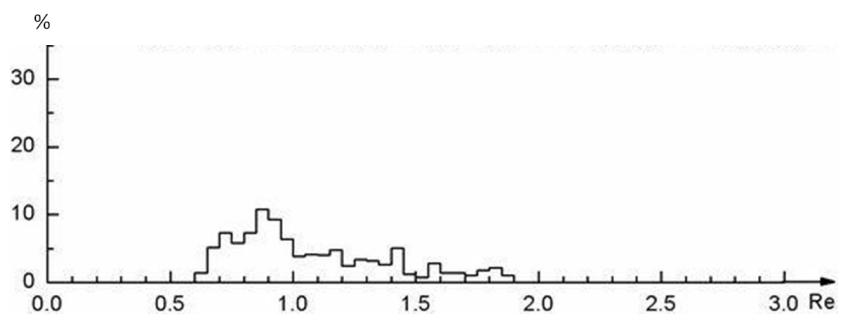

Figure 7. A histogram of vitrinite reflectance of coal blending scheme 2 .

As we can see from figure 7, reduced the content of fat coal in coal, increased coking coal content. The proportion of all kinds of coal and the reflectivity curve of blending coal tend to be reasonable.

Passed small coke oven test.

Results of the test in programme 1: crushing strength $\mathrm{M}_{40}=79.6 \%$; abrasive resistance $\mathrm{M}_{10}=9.6 \%$.

Results of the test in programme 2 : crushing strength $\mathrm{M}_{40}=87.1 \%$; abrasive resistance $\mathrm{M}_{10}=6.5 \%$.

It can be seen that the coke quality of scheme 2 is significantly better than that of scheme 1 .

\section{Conclusion}

1. The reflectance distribution of vitrinite of coal-rock analysis is identification better method for mixed coal, it has obvious effect on the identification of coal quality and the discrimination of coal mixing.

2. The scheme of coal blending can be optimized by using the reflectivity distribution map of synthetic of single kind of coal. Reasonable improvement of the proportion of all kinds of coking coal so that improvement of coke quality.

3. When using coal-rock method to guide coking and predict coke quality, it must be tested no arbitrary application.

\section{Acknowledgements}

The authors would like to acknowledge to financial support from the Guizhou Provincial Science and Technology Project Fund of China (Grant No. QKH GZ (2015) 3014).

\section{References}

[1] WANG X Q chief editor, Coking process [M]. Beijing: Chemical Industry Press, 2015: 32-43.

[2] YAO Z Z, Coking [M], Third Edition, Beijing: Metallurgical Industry Press, 2005: 67-69.

[3] WANG H Y. The development of coal mechanics and coking coal blending technology [J]. Coal Quality Technology, 2004, 6: 39-41.

[4] JIA R M, JI T S. Application of coal lithofacies analysis in coal blending coking [J]. Fuel \& Chemical Processes 2005, 36 (6): 22-24.

[5] XIAO K J, JIA J C, et al. Application of coal rock analysis in coking production.

[6] ZHANG Y Y. apply coal petrography [M]. Beijing: Metallurgical Industry Press, 1990: 138.

[7] ZHU Y G, LI G. Coal chemistry [M]. Beijing: Chemical Industry Press, 2015: 46-70.

[8] SHE J. Study of coal rock recognition methods based on image pro-cessing [D]. Beijing: China University of Mining\& Technology (Beijing), 2014: 11-23.

[9] SUN J P, SHI J. Wavelet-based coal-rock image feature extraction and recognition [J]. Journal of China Coal Society, 2013, 38 (10) 1900-1904.

[10] CHEN P. Nature, Classification and Utilization of Coal in China [M]. Beijing: Chemical Industry Press, 2007, 75-76.

[11] ZHAO X H, ZHOU D F, et al. Application of coal petrography in coal quality evaluation for coking. [J]. Coal Science \& Technology, 2004, (2): 27-28.

[12] ZHANG H, LI ZH, JIANG Y Y. Study on coal and rock identification based on image texture [J]. Coal Technology, 2015, 34 (7): 120-121.

[13] PAN L H, WEI S B. New coking technology [M]. Beijing: Metallurgical Industry Press, 2006: 6 12-13.

[14] XU J, ZHAO J G, et al. The primary index of coal quality inspection and control in modern times [J]. Energy for Metallurgical Industry, 2002, 21 (1): 55-59.

[15] SON Q Y, BAI X F, et al. Application of lithofacies analysis in coal blending identification and control [J]. Fuel \& Chemical Processes, 2004, 31 (3): 130-13.

[16] YAO B Y, The role of coal reflectance distribution map in coking coal blending [J]. Fuel \& Chemical Processes, 2008, (5): 11-15.

[17] YAO B Y, Li D J, et al. The role of various types of coal blending in coking $[\mathrm{J}]$. Fuel \& Chemical Processes, 200738 (6): 1-6. 